\title{
MODEL-BASED ESTIMATION OF AGRONOMIC VALUE RESPONSES TO
} SEASONAL FORECASTS

\author{
Ndizihiwe Prosper*
}

*Corresponding Author: -

\begin{abstract}
: -
Projecting crop yields and aggregate production of the region is of the highest interest for maize production markets which is the source of economic development of the farmers. We used Agriculture Production Systems sIMulation (APSIM 7.10) to simulate the maize yield of Nkotsi region of Rwanda for two seasons SOND and MAM. For this simulation, daily meteorological data of the rainfall, Solar radiation, maximum and minimum temperature are inputs of the model. We demonstrated the impact of the ElNin o-Southern Oscillation (ENSO)phases and the yield, we found that ElNin o phase is good for maize and LaNina lead to the small yield. We compared the simulated yield with observed we realized that they are correlated with $R$ Square of 0.89. We identified cropping practices of profit-maximizing based on climate information. The seasonal rainfall forecasting have been done by Climate Predictability Tools(CPT15) and WeatherMan Version 4.7, utilizing General Circulation Model (GCM) and Enhancing National Climate Services (ENACTS) data from 1985 to 2019.
\end{abstract}

Keywords: - ENSO Phases, Forecast, Rainfall, Maize, Season, Yield 


\section{INTRODUCTION}

\subsection{Necessity of forecasts}

The population of the world is increasing especially in developing countries; Any increase of the number of population means the decrease of agriculture surface (Kelley, 1996). Agriculture being the indispensable activity for living being could be done in the way that it can solve the problem of hanger to the current humanity as well as the next generation. The best way to achieve this, is to strengthen in maximizing the production on the arable land. Among the mechanism to improve yield is to put on land consolidation policy, selection crop according to the soil characteristics, smart system of providing the appropriate fertilizers and seed and climate change based agriculture. Regarding the climate change, the farmers are highly vulnerable due to the undesired climate variation which impacts negatively the agriculture value (Brown, 2000). The climate variability creates uncertainty of crop management mechanism. The farmer must take decision of management with purpose to increase the production using minimum input. With unpredictable climate it become difficult because they are not able to know an appropriate management mechanism. The climate variability also imposes the prices on the market. As it is difficult to estimate the production of the season without climate prediction, it occurs the cases of lank of the market, and the result is to sell the production at small price (Riggs et al., 2005). Unpredictable climate goes as well to the decision makers responsible of advising the farmers about the time of sowing, the type of crops and fertilization and to find the market of the yield. Agronomic sector can be one of the business activities but the barriers include the climate forecast. It is therefore important to have the prediction method for climate then crop production(Riggs et al., 2005).

\subsection{Some work done}

V. Zanella (Zanella et al., 2015) in the work titled" Combining crop sensing and simulation modeling to assess withinfield corn nitrogen stress", accessed the special variation of Nitrogen in north Italy for different agriculture seasons. the modeling and simulation have been carried out in CERESMazes. They managed to simulate the yield of incoming two years based on data of two passed years. In that work the input of the model was the soil properties and crop management. They didn't use the climate data which is going to be used in this work.

F. S. Royce (Royce et al., 2001) in the work tilted" Model-Based Optimization of Crop Management for Climate Forecast Applications", they linked the crop simulation model with a partial budget calculator in view to optimize the economy by variety of crops management. The optimization was based on El Nin o Southern Oscillation (ENSO) where the Global Circulation Model (GCM) has been employed. In the current work, the data in use are from meteorological institution and farmers them selves rather than El Niño climatic data.

James W. Hansen (Hansen et al., 2004) in the work titled "Using a general circulation model to forecast regional wheat yields in northeast Australia", he demonstrated a method of using GCM-based seasonal to predict yield of wheat in Australia. The used historical district rainfall data and predicted yield by linear regression with observed weather as function of GCM predictors.

\subsection{Estimating value of seasonal forecasts for crop management}

Value of forecast information is generally defined as the Expected outcome of best response to new information (a climate forecast), minus expected outcome of best response to prior information (the climatological distribution) (Hansen et al., 2009). The above definition is explained in the following relation

$$
V_{F}=E\left\{U\left(\Pi\left(X^{*} \mid F ; \theta, e\right)\right)\right\}-E\left\{U\left(\Pi\left(X^{*} \mid \Theta ; \theta, e\right)\right)\right\}
$$

Where $V_{F}$ stands for forecast information value, $E$ is the expectation, $U$ is the utility, $\Pi$ is the net income, $X^{*}$ is the management $F$ is the forecast $\theta$ represent the weather and $e$ is the environment variable which include the soil and moisture and Nitrogen situation. The management of the crop is subjected to the climatic situation. Uncertain condition lead to the uncertain management. With a believable information an appropriate management decision will be taken and will finally improve the productivity. The value of crop can generally be estimated as a function of Decision management, meteorological variables and the decision makers initial weather. It is summarized by

$$
U\left[Y(I, E, X), W_{o}\right]
$$

$U$ is the Utility, $Y$ is the Profit which is also a function of income $I$ and expanses $E, X$ is the vector that represents decision management that contains production factors the combination of the $C$ is the meteorological variables and $W_{o}$ the Decision makers of initial weather. The farmers are facing the problem of uncertain climatic variability for all agriculture journey of the season. At the time of harvest, the expected utility is dependent of the sum of climate variation. We can now written as (Meza et al., 2008)

$$
E\left\{U\left[Y(I, E, X), W_{o}\right]\right\}=\int U\left[Y(I, E, X, C), W_{o}\right] f(C) d C
$$

From 1.3 and 1.3 we can deduce the following expression

$$
E V O I=E\left\{U\left[Y\left(I, E, X^{+}\right), W_{o}\right]\right\}-E\left\{U\left[Y\left(I, E, X^{*}\right), W_{o}\right]\right\}
$$


With $E V O I$ expectation of the value of information, $U$ is the utility function, $Y$ the profit after agriculture harvest, $X^{+}$the management based of forecast information and $x^{*}$ is the management without forecast. This tells us that the value of such information is estimated as the difference of the profit from the yield obtained using the forecast information and the yield obtained without using forecast. This can be expressed by the following function.

\subsection{Calculating gross margin}

The gross margin is generally defined as the difference between cost of the commodity and the expenses until the market. In our context is the deference the total price selling of the yield at market and the all the spends on the crop until the end. The formula below can used to compute is value.

$$
\pi=P Y(X, \theta, e)-C_{X}
$$

With $\mathrm{P}$ is the price, $\theta$ the observed weather $\mathrm{CX}$ is the cost spent for practice of the management $\mathrm{X}$ for more that one crop, the computation of the sum can give

$$
\sum_{i=1}^{n} \pi_{i}=\sum_{i=1}^{n}\left(P_{i} Y\left(X_{i}, \theta, e\right)-C_{X_{i}}\right)
$$

By detailing the cost of management, one can write also can give (Royce et al., 2001)

$$
\pi_{i}=(Y \times p)-d \times s f \times c s-n \times c n-a p-c p \times y \times p-f
$$

$d$ is the density of the plant, $s f$ seed factor, $c s$ cost of the seed, $n$ amount of nitrogen $c n$ the cost of nitrogen per kg, $c p$ the cost proportional to income and $f$ is the fixed cost.

Equation 1.4 shows the value of information. Our concern is to choose management system that maximize the gross margin with or without climate forecast. This takes us to the optimization problem that can be written as follows:

$$
\begin{aligned}
& \max _{X} P Y(X, \theta, e)-C_{X} \\
& \max _{X^{+}} P Y\left(X^{+}, \theta, e\right)-C_{X^{+}} \\
& \text {s.t. constraints }
\end{aligned}
$$

The constraints that can be considered in this case is the maximum priceof the yield per kilogram, the minimum cost of the management.

\section{Methodology}

\subsection{Select field trial sites and data collected}

The selected field are sector Nkotsi sector in Musanze district of northern province and Ruhuha in Bugesera. Nkotsi is located on 30.1 longitude, -1.3 latitude and $1865 \mathrm{~m}$ of elevation, while Ruhuha is on 30.38 longitude, -2.43 latitude and $1594 \mathrm{~m}$ of elevation.

From Meteo-Rwanda requested the gridded data of climate parameters (rainfall, maximum temperature, minimum temperature and solar radiation) of the recent three years which correspond to six agriculture seasons. From RAB we got the data of crop production of Nkotsi sector from 2000 to 2019. Indeed, to be able to put into consideration the economic cases, We used the data of all kind of investment that the farmers invest since the preparation of land until the final product including pre-harvesting expenses and the price of the yield on the market.

\subsection{Climate seasonal forecast}

For this step, the General Circulation Model (GCM) and ENACTS data have been used for seasonal prediction of September, October, November and December (SOND)and March, April and May (MAM) by CPT. sectionAveraging monthly climate To find the values of climatic element in selected region we have used Weather Man within Decision Support System for Agronomic Technology Transfer (DSSAT).

\subsection{Yield simulation}

We used of crop modelAPSIM the input data are as follows:

- Daily weather time series (rainfall, Tmax, Tmin, solar radiation)

- Soil properties, by layer

- Cultivar parameters

- Management decisions or rules

\subsection{Computation of gross margins}

This computation is based on equation 1.4 and the prices data will be used.

\subsection{Identification of optimal management without and with forecasts}

For this task, optimization equations 8 will be used for withoutforecast case and 9 will be used for withforecast case. 


\section{Results and Discussion}

Analysis has been conducted by using DSSAT, CPT to forecast the climate, APSIM of to simulate the yield and we have also used RStidio to compare between farmer profit of both forecast and without forecast cases. For DSSAT, it has been used two cases. The first case is for general analysis of the Maize yield with climatic elements which is Seasonal Analysis, the second for obtaining values of climatic element in the chosen regions using WeatherMan.

\subsection{General Impact of Climatic Elements on Maize}

In this section, we look at the general behavior of the Maize production with the rainfall, maximum temperature and minimum temperature. For this purpose the seasonal analysis window found is DSSAT.

Figure 3 shows that the yield increases as evapo-transpiration decreases. The relationship is represented by the function

$$
Y=4017.932-24 E T+0.041 E T^{2}
$$

The function shows that as evapo-transpiration decreases, the yield increases. This is logic because the soil water is the base of the plant nutrients. So as this water decreases by evapo-transpiration, the nutrient reduces. ET stands for Evapotranspiration, $Y$ is the yield. Agriculture yield is also dependent of the minimum temperature. Figure 2 shows that the variation of the maximum

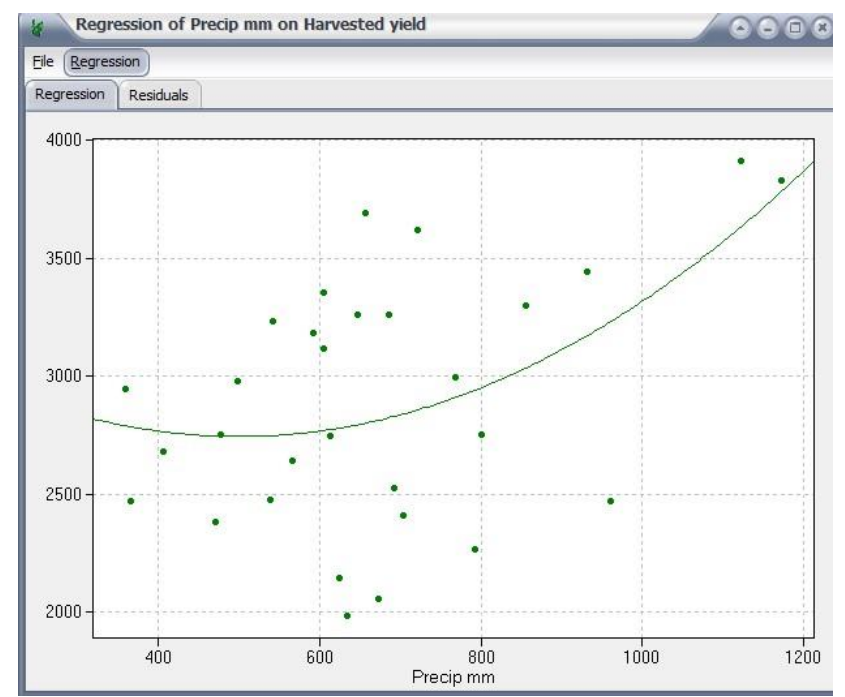

Figure 1: Relationship of Rainfall with Maize Yield

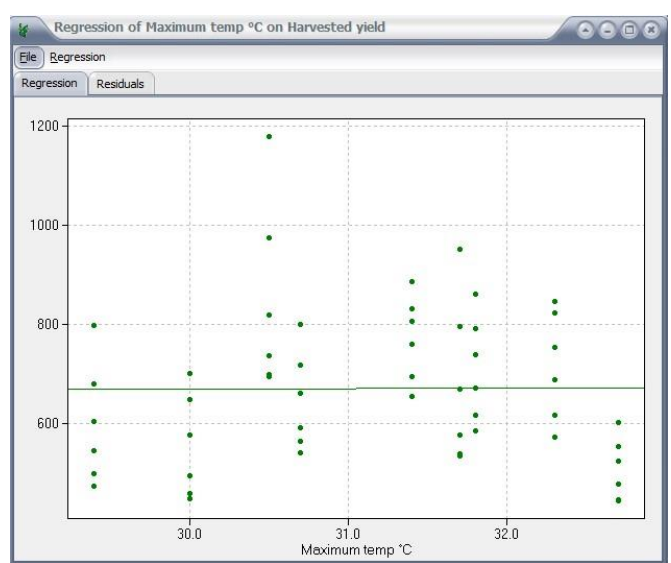

Figure 2: Relationship of Maximum Temperature with Maize Yield 


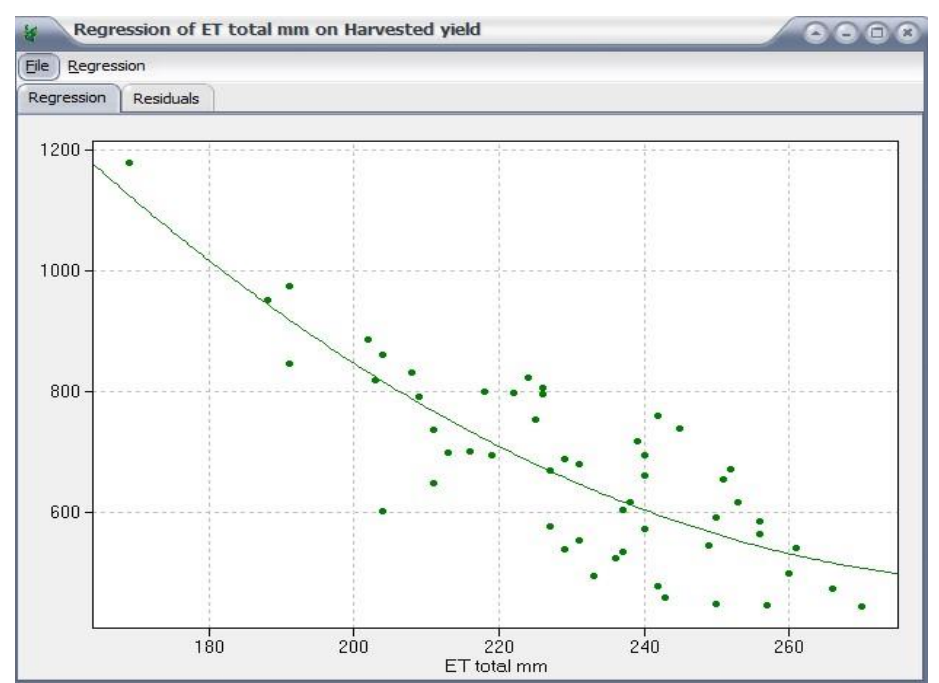

Figure 3: Relationship of Evapo-transpiration with Maize Yieldtemperature leads to the small variation of the yield. The relationship is represented by the function

$$
Y=0.748 \text { Tmax }+646.757
$$

The dispersion of the elements which is high is because we neglected important elements which are crop management and treatments that are very important. In this analysis, we found that precipitation and evapo-transpiration pray a big role on the yield. In the next section we forecast the precipitation. In this work, we will not forecast evapo-transpiration however the farmers could reduce it by mulching practice.

\subsection{Rainfall forecast}

To forecast the climate, CPT is in use. The GCM data from 1985 to 2019 have been downloaded and used as explanatory (X) Variables and ENACTS data of the same period as response (Y) Variables. By use GCM maximum temperature, we take into account the effect of increase of temperature in Pacific Ocean (ENSO Phases) on the climate of the Africa. Both SOND (September October November December) and MAM (March Apri, May) seasons have been foretasted. Following results have been obtained. Looking at figure 4, we can see that the there is high probability of the rain to be Below, Normal and Above are respectively 35\%,33\% and 32\%. Looking at figure 5, we can see that the probability of the rain to be Below, Normal and Above are respectively $40 \%, 23 \%$ and $37 \%$.

The distribution of the rainfall in all the country can be seen by looking at figure 6 and 7. For SOND, dominant color on the map has between $40 \%$ to $45 \%$ probability. Small region to the Northern western and smallest Northern east have probability of below normal rainfall.

For 7 of MAM,the dominate color represent the probability of $40 \%$ of being above normal.

In this section we foretasted the quantity of the rainfall compared to the means of regions, but no exact ranges of that precipitation. In the next section, we are going to use data of recent years of the chosen region to oversee the variation of precipitation, minimum temperature maximum temperature and solar radiation.

\subsection{Climate in Ruhuha and Nkotsi Regions}

In this section, WeatherMan Version 4.7.0.0 has been utilized. Weather data of recent years since 1985 to 2019 have been used for both Ruhuha

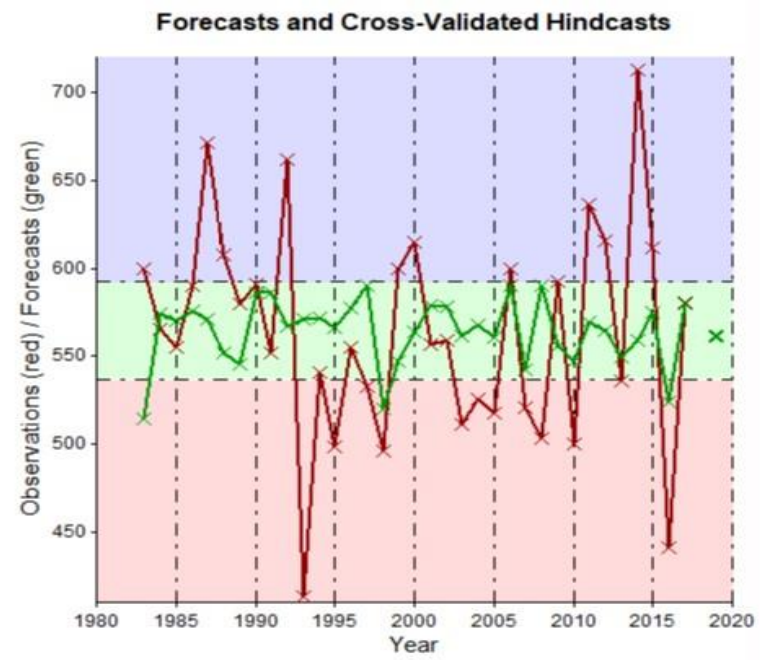

Figure 4: Probabilistic Forecast and Cross-Validation for next SOND season 
and Nkotsi regions, and the coordinates Latitude, Longitude and Elevation have considered to get the results. The monthly means of the solar radiation, maximum temperature, minimum temperature and the rainfall the two region are found in the tables 2 and 3. Both tables 2 and 3 show that the small rainfall is in July and the big rainfall is in September as it is clearly shown in the graph 8 . The computation of the average seasonal rainfall, is obtained but summing the average monthly rainfall of the months that compose the season. It gives for:

- Nkotsi: SOND:479.1 and MAM:456

- Ruhuha: SOND: 425.3 and MAM: 4251

In this section, we found the monthly averages of the climate in Nkotsi and Ruhuha. Combining with the forecast done in the previous, It is possible to know the range of the seasonal rainfall. The next is work on treatment techniques to improve the production. In the following section we use APSIM for crop simulation.

\section{Probabilistic forecasts}

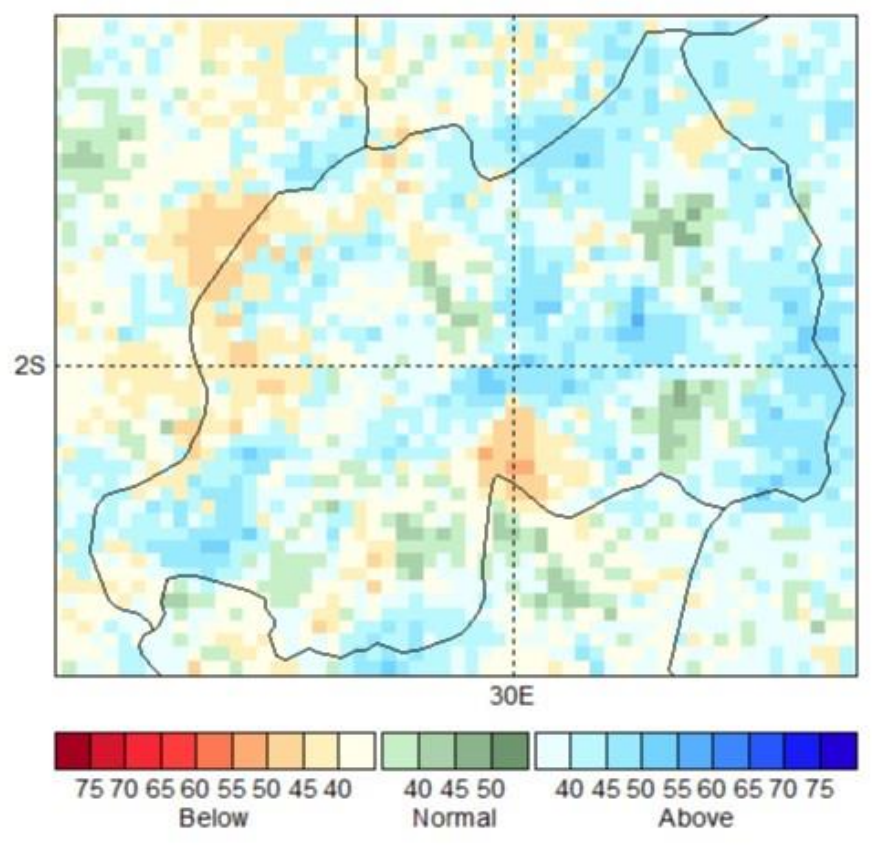

Figure 5: Rainfall Forecast for next MAM season

\section{Probabilistic forecasts}

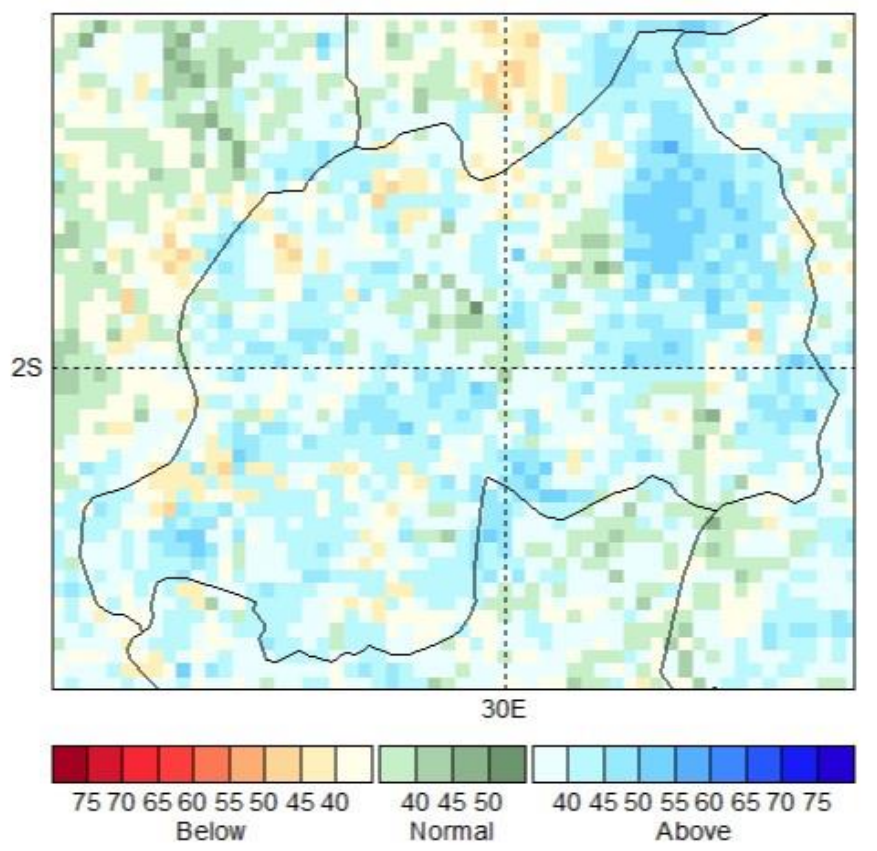

Figure 6: The rainfall forecast for next SOND season 


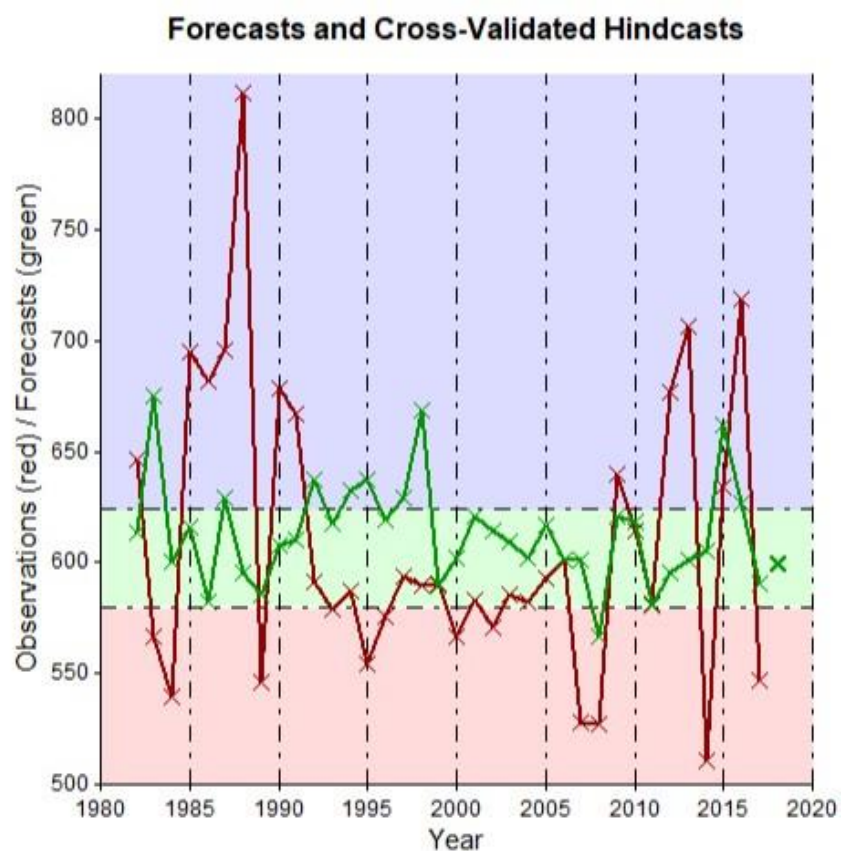

Figure 7: Rainfall Forecast and Cross-Validation for next MAM season

Table 1: Monthly Averages Rainfall of Ruhuha Region

\begin{tabular}{lllll}
\hline Month & $\operatorname{Srad}\left(\mathrm{Wh} / \mathrm{m}^{2}\right)$ & $\operatorname{Tmax}\left({ }^{\circ} \mathrm{C}\right)$ & $\operatorname{Tmin}\left({ }^{\circ} \mathrm{C}\right)$ & $\operatorname{Rain}(\mathrm{mm})$ \\
\hline Jan & 17.7 & 22.3 & 13.2 & 61.5 \\
Feb & 18.2 & 22.6 & 13.5 & 98.3 \\
Mar & 18.1 & 22.4 & 13.4 & 132.5 \\
Apr & 16.5 & 21.2 & 13.2 & 173.9 \\
May & 15 & 20.9 & 13.4 & 118.7 \\
Jun & 15.1 & 21.1 & 12.8 & 27.7 \\
Jul & 16.1 & 21.9 & 12.7 & 6.7 \\
Aug & 17.3 & 22.8 & 13.4 & 49.1 \\
Sep & 18 & 22.5 & 13.3 & 110.5 \\
Oct & 17.9 & 22.1 & 13.2 & 115.6 \\
Nov & 17.2 & 21.5 & 13 & 116.6 \\
Dec & 17.1 & 21.8 & 13.1 & 82.6 \\
\hline
\end{tabular}

Table 2: Monthly Averages Rainfall of Ruhuha Region

Table 3: Monthly Averages Rainfall of Nkotsi Region

\begin{tabular}{lllll}
\hline Month & $\operatorname{Srad}\left(\mathrm{Wh} / \mathrm{m}^{2}\right)$ & $\operatorname{Tmax}\left({ }^{\circ} \mathrm{C}\right)$ & $\operatorname{Tmin}\left({ }^{\circ} \mathrm{C}\right)$ & $\operatorname{Rain}(\mathrm{mm})$ \\
\hline Jan & 19.2 & 25.6 & 15 & 71.6 \\
Feb & 19.8 & 25.4 & 14.7 & 94 \\
Mar & 19.5 & 24.9 & 14.5 & 185.5 \\
Apr & 18.4 & 25.1 & 15.1 & 136.6 \\
May & 17 & 24.8 & 15.1 & 133.9 \\
Jun & 17.3 & 25 & 14 & 59.1 \\
Jul & 19.1 & 25.7 & 12.7 & 14.5 \\
Aug & 19.3 & 26 & 14.2 & 61.2 \\
Sep & 19.4 & 25.6 & 14.9 & 93.5 \\
Oct & 20 & 25.8 & 14.8 & 101.5 \\
Nov & 24.8 & 24.8 & 14.8 & 127 \\
Dec & 24.4 & 24.4 & 15 & 157.1 \\
\hline
\end{tabular}




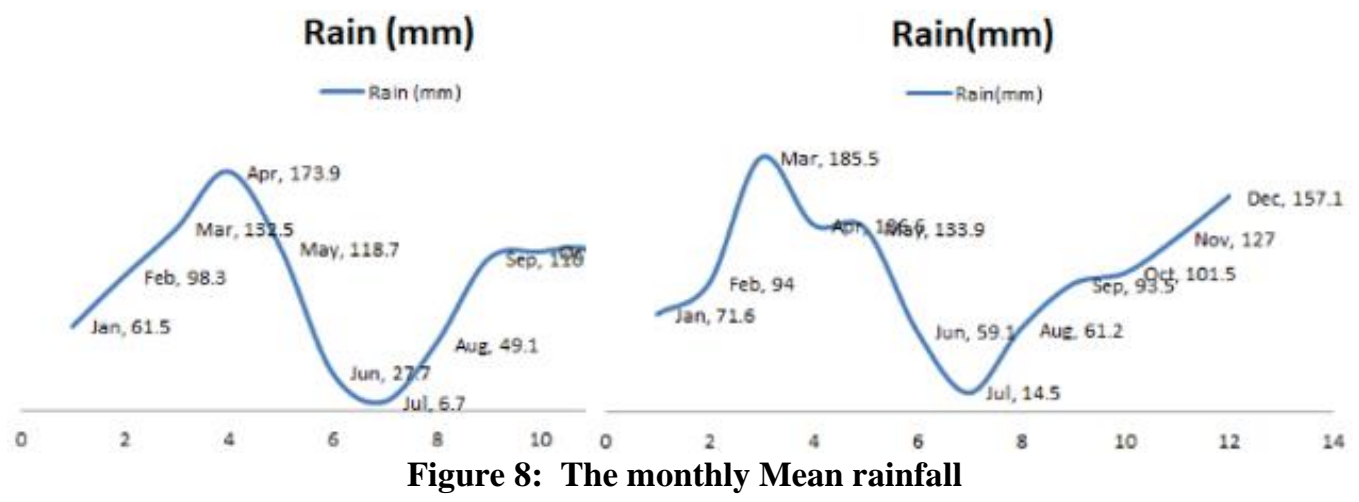

\subsection{Yield simulation for different crop managements}

The comparison of the different crop management is now going to the investigated by using APSIM. For sowing date, method of cropping and sowing depth there is no requirement of financial capacity. It is an important thing to look at. It this work the researcher didn't varies them.

Among other management that author takes into account that require finance following are the following: Sowing period: 20 September to 10 October Sowing density of 5.3 plant per $\mathrm{m}^{2}$ Manure of $500 \mathrm{~kg}$ per hectare Top Dress fertilizer is $\mathrm{NO}_{3} \mathrm{~N}$ $150 \mathrm{~kg} / \mathrm{ha}$. Sowing spacing $40 \mathrm{~mm}$ Sowing depth is $30 \mathrm{~mm}$

This set of treatment mechanism is in the case of the no climatic information study.Note that for MAM season simulation has been done with the same managements except sowing period of 25 March to 05 April. After simulation, the yield for various treatments as presented in the figure 9, it shows that the yield of SOND season if higher that MAM. We simulated yield of sector

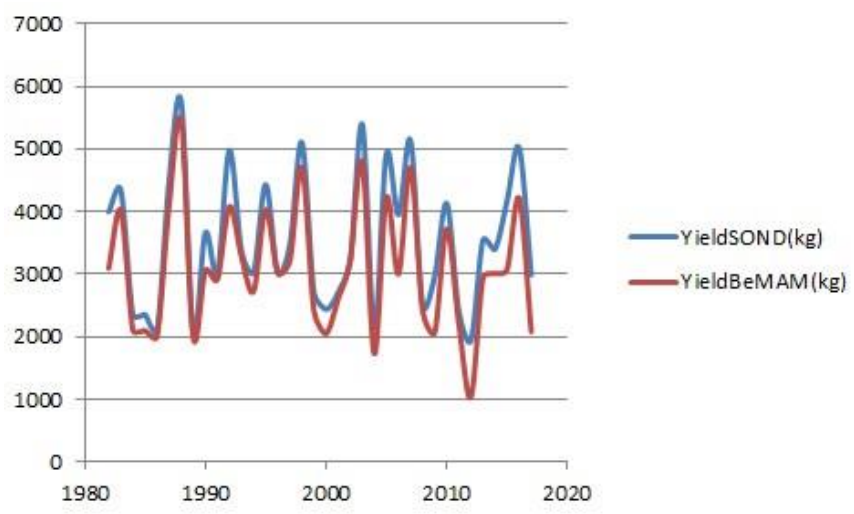

Figure 9: Simulated yield of different years

from 1985 to 2019 with the same crop management without seasonal rainfall information. The results defer because the climatic elements are not the same long of the time in that region.

Knowing the phases of ENSO year and corresponding rain, we choose additional managements.

With seasonal rainfall information, we practice additional management: LaNina and Neutral: 1SARM081, this is chosen because of its adaptive altitude of $[1200-1500 \mathrm{masl}]$ (the chosen region has 1.483 masl) and its small maturity days (110 day). For ElNino. I used the SC637 because it accept much rain/water. Irrigation: This is to compensate the needed water for 1SARM081 from $384.8 \mathrm{~mm}$ to $600 \mathrm{~mm}$ for NaNina and from 455.7 to $600 \mathrm{~mm}$. This set of treatment mechanism gives results plotted in the figure 10 and show the improvements on the yield side.

\subsection{Influence of the ENSO Phases on the yield}

3.5.1. Rainfall and ENSO Phases

Let us first show the rain-fed in ENSO phases in figure11It shows that 


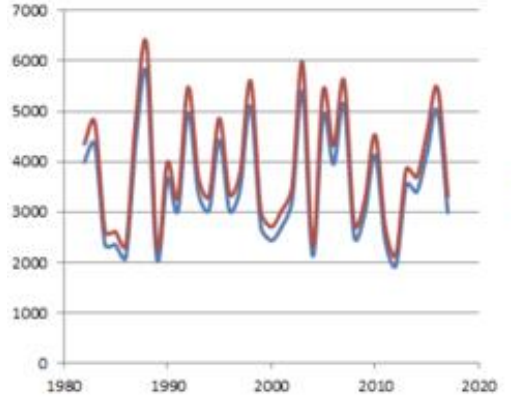

(a) For SOND

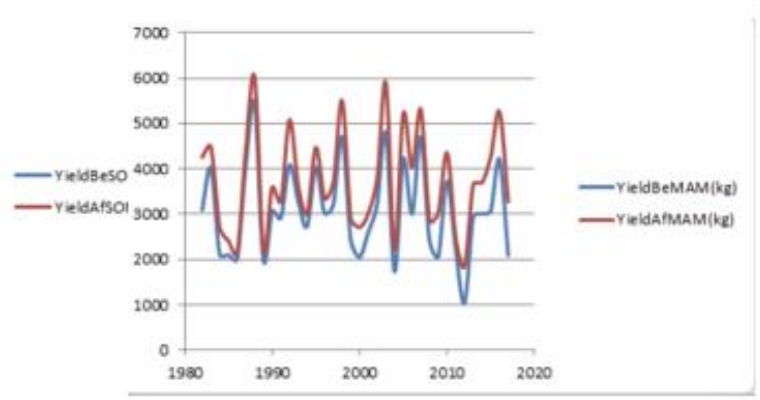

(b) For MAM

Figure 10: Simulated yield with climate info

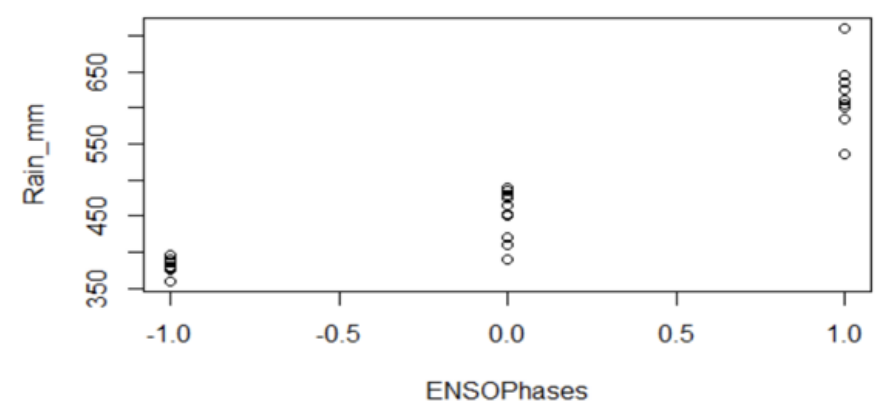

Figure 11: Yield as a function of the SOND rainfall 1985-2019

there is high for ELNiño however it can be high for neutral in some years as summarized in table 4 .

\subsubsection{Yield and ENSO Phases}

Simulated yield from APSIM are combined with September to December total rain-fed of 1985 to 2019, taking into account the ENSO Phases in view to see the correlation using RStidio for Nkotsi Region. Obtained results are mmarized in the table 5.

Table 5 shows that the minimum of total rainfall Sep-Dec is $360 \mathrm{~mm}$ Correspond to the minimum yield (1936 kg) are at LaNina Phase of 1985. The maximum of total rainfall Sep-Dec (710 mm) Correspond to the min-

Table 4: The summary of the rain for all ENSO Phases years

\begin{tabular}{lll}
\hline Year & ENSOPhase & Rain \\
\hline Min. :1982 & Min. :-1 & Min. :360.0 \\
1st Qu.:1991 & 1st Qu.:-1 & 1st Qu.:390.0 \\
Median :2000 & Median : 0 & Median :465.0 \\
Mean :2000 & Mean : 0 & Mean :484.9 \\
3rd Qu.:2008 & 3rd Qu.: 1 & 3rd Qu.:600.0 \\
Max. :2019 & Max. : 1 & Max. :710.0 \\
\hline
\end{tabular}

Table 5: The summary of simulated yield for all ENSO Phases years

\begin{tabular}{llll}
\hline Year & ENSOPhase & Rain & Yield \\
\hline Min. :1982 & Min. :-1 & Min. :360.0 & Min. :1936 \\
1st Qu.:1991 & 1st Qu.:-1 & 1st Qu.:390.0 & 1st Qu.:2657 \\
Median :2000 & Median : 0 & Median :465.0 & Median :3379 \\
Mean :2000 & Mean : 0 & Mean :484.9 & Mean :3531 \\
3rd Qu.:2008 & 3rd Qu.: 1 & 3rd Qu.:600.0 & 3rd Qu.:4363 \\
Max. :2019 & Max. : 1 & Max. :710.0 & Max. :5749 \\
\hline
\end{tabular}

imum yield $(5749 \mathrm{~kg})$ are at EINino Phase of 2019. For Neutral Phase we can have average rain of [465.0 - 484.9] $\mathrm{mm}$ that correspond to the yield of [3379-3531] kg. It make us to say that the increase of the rainfall imply the increase of the yield of maize as it is simply seen on the figure 12 . Figure 


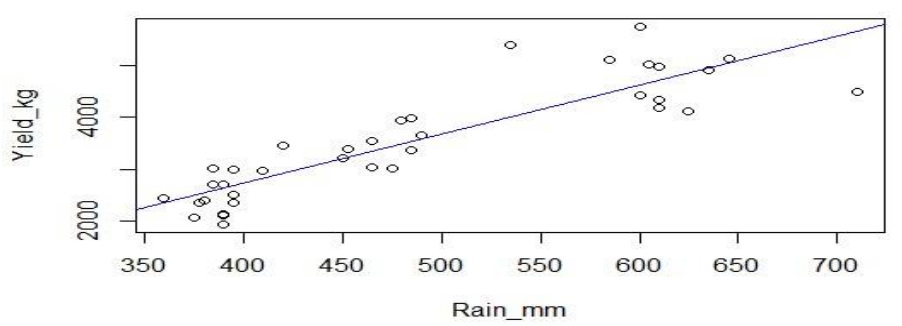

Figure 12: Yield as a function of the SOND rainfall 1985-2019

12 shows that the yield of Maize in SOND season does depend on the total rainfall of September to December. They are some high values of the rain that correspond to the small yield; This is the case high level of ElNino. To maximize the yield, some mechanisms that reduce the water are recommenced.

To see the influence of the EINino, Neutral and LaNina, we look at the figure 13 The details on the change of the yield with ENSO Phases can be regarded on 14. It shows that many values are less than the mean for SOND but fro the case of MAM is opposite; for the case of ElNin o. For Neutral the standard deviation is small for MAM than SOND and the mean yield is centered in the middle of other yield.

\subsection{Computation of the value of information}

The Value of Information (VOI) is defined as the difference between the yields obtained after applying additional management based on climate information and the without climate information. Its calculated in yield(kg) and in RWF. It is computed based on equation (1.3) and is plotted on the figure 15.

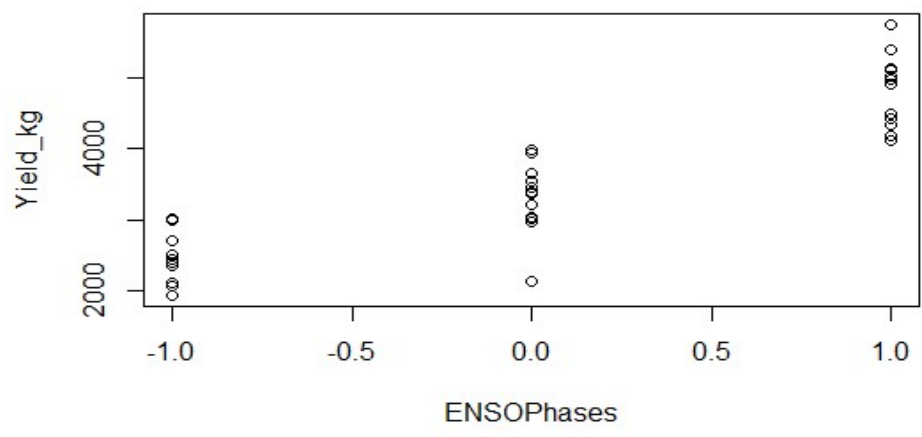

Figure 13: Yield variation for ENSO Phases

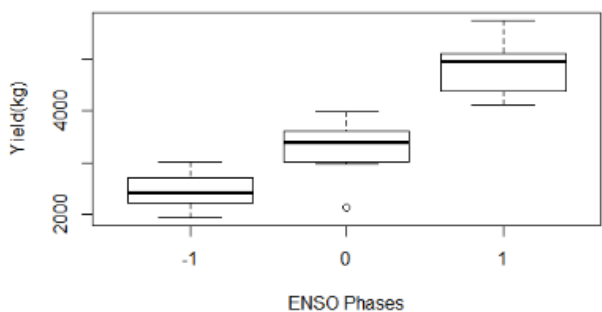

(a) For SOND

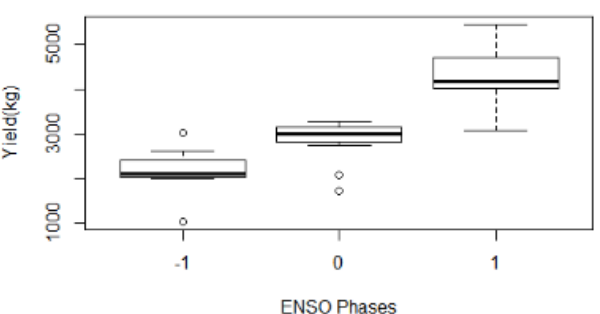

(b) For MAM

Figure 14: Yield with ESNO phases

\subsection{Comparison of simulated and Observed yield}

We used available field results recorded by MINAGRI for both SOND and MAM seasons.

\subsection{For SOND season}

The results are shownIn the table 6, we can see that the yield in general doesn't depend on year (correlation coefficient of 0.00799 and 0.006); but depends of ENSO Phases (correlation coefficient of 0.878 and 0.89) and Rain (correlation coefficient of0.89 and 0.88 ). 


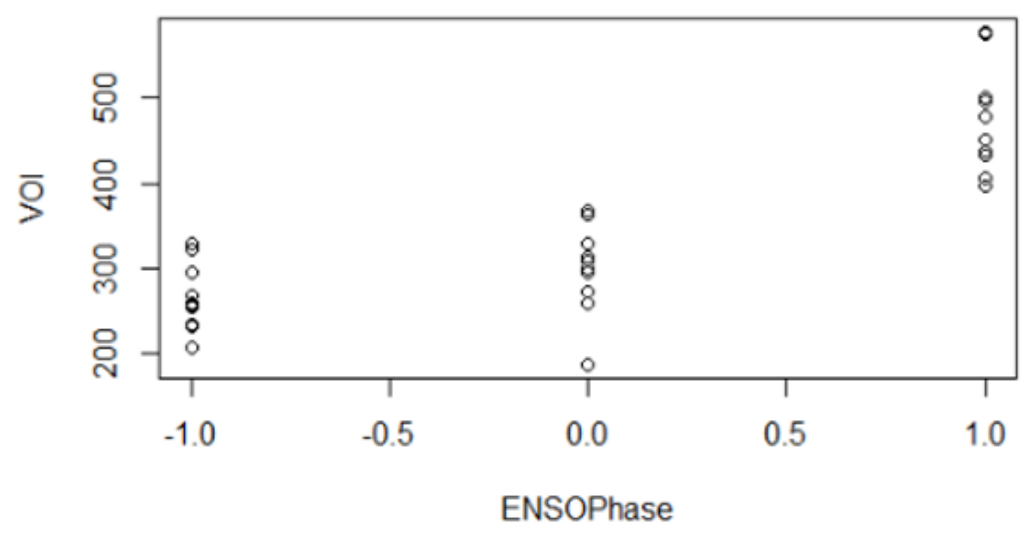

Figure 15: Yield as a function of the SOND rainfall 1985-2019

Table 6: Correlation table of simulated and observed yield for SOND season

\begin{tabular}{llllll}
\hline & Year & ENSOPhase & Rain & Yield Sim & Yield Ob \\
\hline Year & 1 & & & & \\
ENSOPhase & 0.0918038 & 1 & & & \\
Rain & 0.1874832 & 0.922159258 & 1 & & \\
Yield Simulated & 0.079912 & 0.878314442 & 0.89546415 & 1 & \\
Yield Observed & 0.0604265 & 0.895646594 & 0.88701481 & 0.984993798 & 1 \\
\hline
\end{tabular}

Table 7: Correlation table of simulated and observed yield for MAM season

\begin{tabular}{llllll}
\hline & Year & ENSO & Rain & Yield & Observed \\
\hline Year & 1 & & & & \\
ENSO & 0.091804 & 1 & & & \\
Rain & 0.180513 & 0.95214104 & 1 & & \\
Yield & -0.08052 & 0.82141029 & 0.76976 & 1 & \\
Observed & -0.03882 & 0.76711714 & 0.7566153 & 0.967968398 & 1 \\
\hline
\end{tabular}

Table 8: Regression Statistics of Simulated and observed yield SOND

\begin{tabular}{ll}
\hline Regression Statistics & \\
\hline Multiple R & 0.947805832 \\
R Square & 0.898335895 \\
Adjusted R Square & 0.895345774 \\
Standard Error & 350.6849096 \\
Observations & 36 \\
\hline
\end{tabular}

Table 9: Regression Statistics of Simulated and observed yield SOND

\begin{tabular}{ll}
\hline Regression Statistics & \\
\hline Multiple R & 0.946413697 \\
R Square & 0.895698885 \\
Adjusted R Square & 0.892631205 \\
Standard Error & 332.8483256 \\
Observations & 36 \\
\hline
\end{tabular}

On the figures 16 and 17, one can see that observed yield is less that simulated; it is due to the implementation of practices errors so it requared to calibrate. The plot also shows that starting to $640 \mathrm{~mm}$ of the rainfall, the yield starts to decrease and the pick yield is within $[500-600] \mathrm{mm}$. the correlation is shown in the table 6 . 


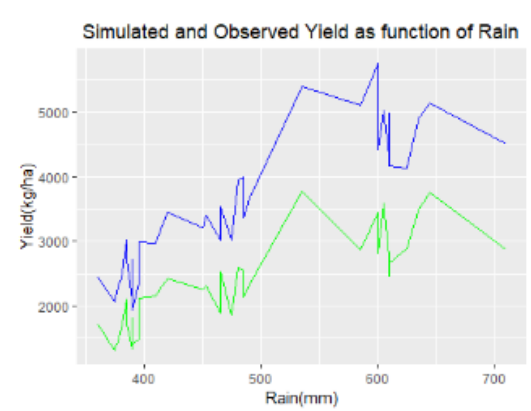

(a) For SOND Season

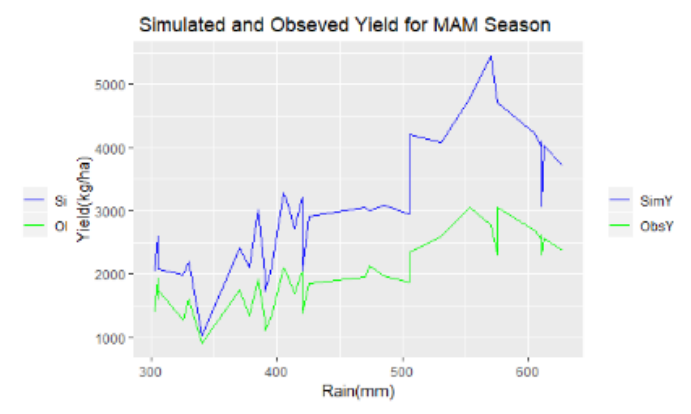

(b) For MAM Season

Figure 16: Simulated and observed Yield as function of rain

Let us also look at how they vary with time on the figure17which showsthat they vary in in the same way however simulated yield is less than observed one.

\begin{tabular}{llllll}
\hline Min & 1stQu & Median & Mean & 3rdQu & Max \\
\hline 1317 & 1744 & 2274 & 2331 & 2782 & 3774 \\
\hline
\end{tabular}

Table 10: Description of observed yield SOND

Table 11: Description of observed yield MAM

\begin{tabular}{llllll}
\hline Min & 1stQu & Median & Mean & 3rdQu & Max \\
\hline 908 & 1608 & 1942 & 1981 & 2342 & 3051 \\
\hline
\end{tabular}

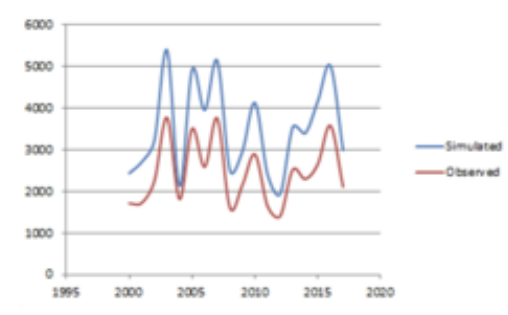

(a) For SOND

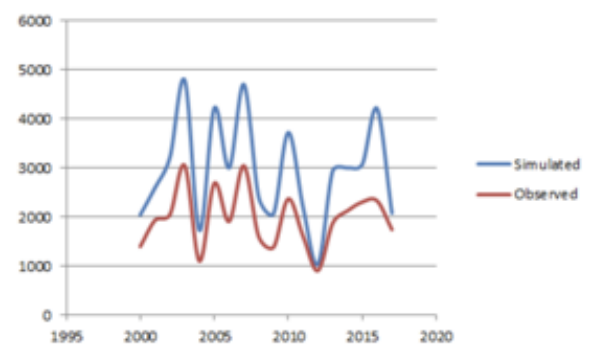

(b) For MAM

Figure 17: simulated and observed

Descriptive statistical summary is also shown by table10,11,12and13.

\section{Calibration}

In the previous section we compared the simulated and observed yield. They do vary in the same way with years and rain, however the distance between the two is high, simulated is greater than observed. Calibration is done by working on practices 4 . That have been utilized to simulate. We change until they become close. A multiplicative factors of around 0.7 is deduced by changing these managements as below:

- Sowing period: 30 September to 20 October

- Sowing density of 5.3 plant per $m^{2}$

- Manure of $300 \mathrm{~kg}$ per hectare 
Table 12: Description of Simulated Yield SOND

\begin{tabular}{llllll} 
Min & 1stQu & Median & Mean & 3rdQu & Max \\
\hline 1317 & 1744 & 2274 & 2331 & 2782 & 3774 \\
\hline
\end{tabular}

Table 13: Description of simulated Yield MAM

\begin{tabular}{llllll}
\hline Min & 1stQu & Median & Mean & 3rdQu & Max \\
\hline 1036 & 2178 & 3010 & 3092 & 4016 & 5442 \\
\hline
\end{tabular}

- Top Dress fertilizer isNO3N100kg/ha.

- Sowing spacing $40 \mathrm{~mm}$

- Sowing depth is $30 \mathrm{~mm}$

The results are plotted in18and summarized in the table 14.

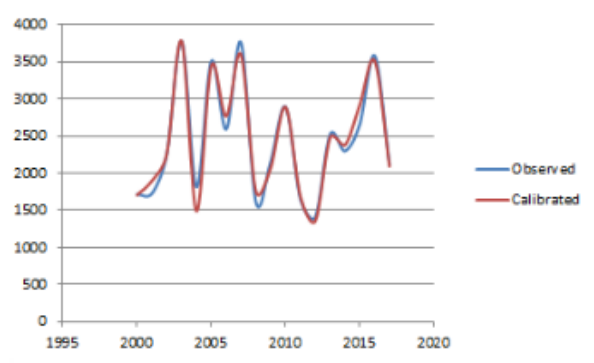

(a) For SOND

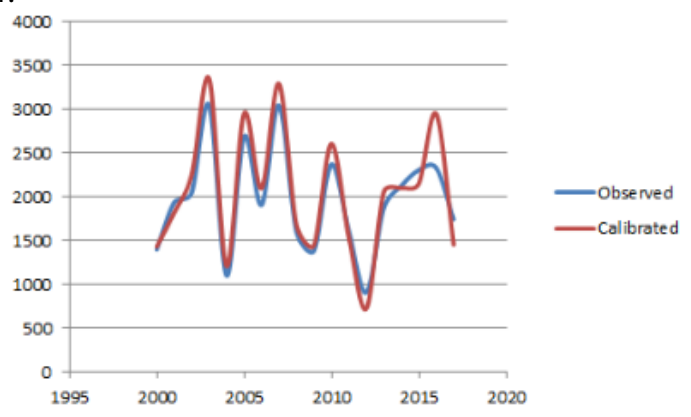

(b) For MAM

Figure 18: Calibrated simulated and observed yield with time

\section{Economic Analysis}

Looking at figure 10 of the previous subsection; one can see that the yield increases however the management requirements have also increased. The diagram 19 is an example which indicate that crop management for increasing the production is not always economic.

In this section we compare the two cases, we use the prices of the one kilogram of the yield, the fertilizers and seed then we compute the profit.

Table 14: Summary of calibrated and observed

\begin{tabular}{lll}
\hline F-Test Two-Sample for Variances & & \\
\hline & Observed & Calibrated \\
Mean & 2331.416667 & 2471.84 \\
Variance & 488504.5929 & 575802.393 \\
Observations & 17 & 17 \\
df & 16 & 16 \\
$\mathrm{~F}$ & 0.848389306 & \\
$\mathrm{P}\left(\mathrm{Fi}_{\mathrm{f}} \mathrm{f}\right)$ one-tail & 0.314683696 & \\
$\mathrm{~F}$ Critical one-tail & 0.56910677 & \\
\hline
\end{tabular}

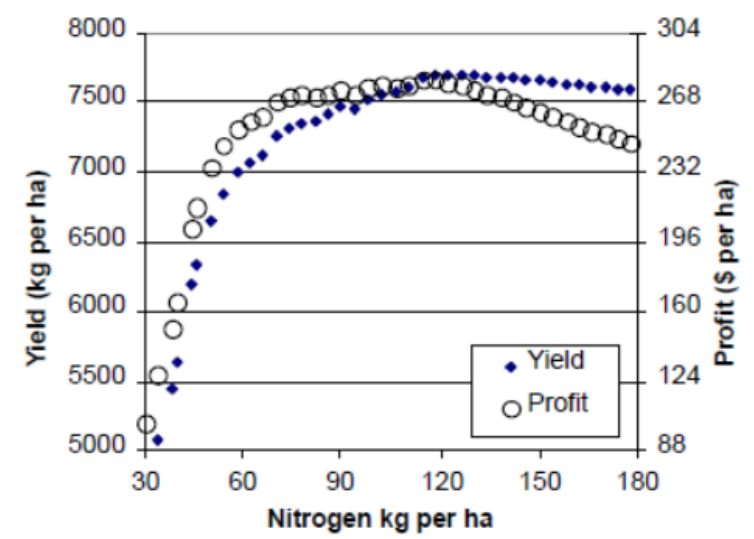

Figure 19: Profit and Yield respect to the Nutrient (Royce et al., 2001) 
Equation 1.4 presented in the second chapter has been utilized but some parameter like pesticide cost is not considered and labor cost has been estimated.

The value of information is shown in figure20and 21 .

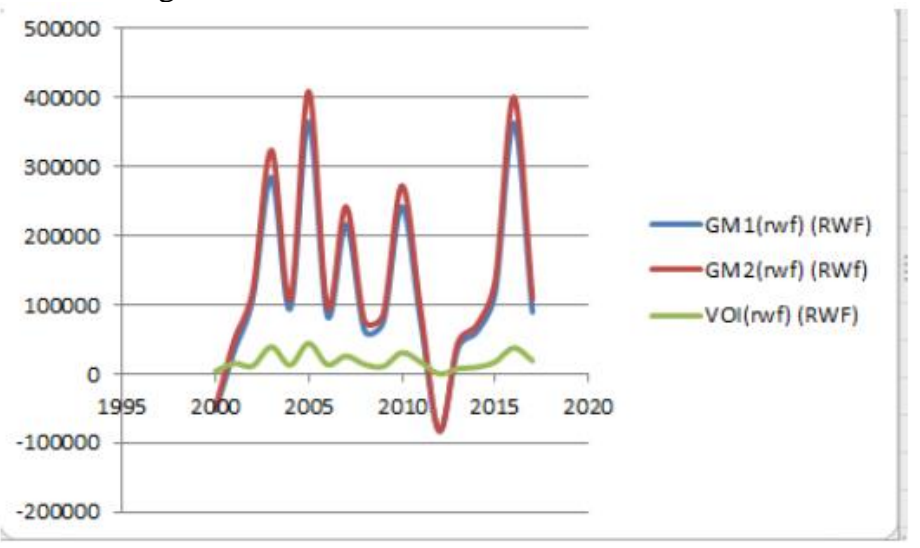

Figure 20: VOI for SOND

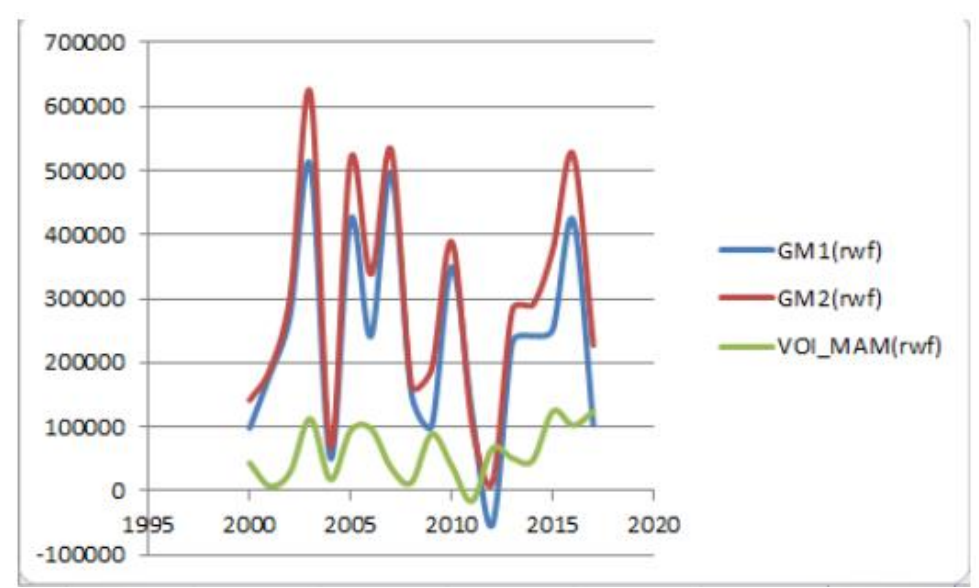

Figure 21: VOI for MAM

The difference of two season is shown by figure22, which clarify show that the benefit is high for MAM than SOND. The prices used are as follows:

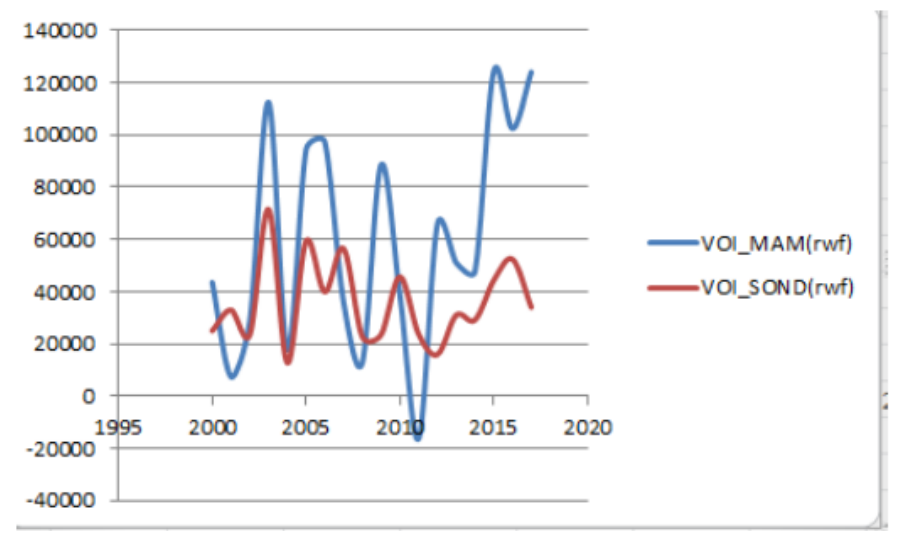

Figure 22: Comparison of VOI for SOND and MAM

- Price of one kilogram of fertilizer (urea):360RWF

- One kilogram of manure:20RWF

- One kilogram of seed of maize:520RWF

- The price of labor without and with additional management are estimated to be 200,000 and 240,000RWF respectively. They show clearly that better management leads to the increase of the yield and benefit in terms of money.

\section{Conclusion}

In the current work, we simulated the yield of maize by using APSIM in 3.4. This simulation demonstrated that yield is depends on climatic conditions especially the rainfall. 
Analysis of ENSO conditions impact on the yield done in 5, demonstrated that the ElNiño phase leads to the high yield compared to other phases, where as the Neutral experiences the small yield than ElNin o but high that LaNina for the two chosen regions. We realized that the change of crop managements based on climatic information improves the yield. Economic studies have proven that the practices of climatic bases managements can give additional profit to the farmers; It is therefore important to know the climatic information buy forecasting.

In this work also, we foretasted the rainfall in 3.2 for SOND and MAM in Rwanda. The results gave the colors showing the whether we will have above normal, below normal and normal rainfall. This is important information because by using seasonal averages that we have found in section 3.3, it is possible to know the range of the rainfall of the next planting season.

All these imply that the prediction of the maize yield is feasible and different climate based crop managements aimed to improve the production is can be tested and applied in Rwanda. This would be the solution of projecting the economy states of population involved in agriculture sector and is the key point implementing agriculture business. It can also solve the problem of market that the farmers face rooted to unpredictable high production.

\section{References}

[1].Douglas R Brown. A review of bio-economic models. Cornell African Food Security and Natural Resource Management (CAFSNRM) Program, 102, 2000.

[2].S Coulter, Stan Lalor, Contributors Stephen Alex, Alastair Black, Andy Bol, Jim Burke, Owen T Carton, Brian S Coulter, Noel Culleton, Pat Dillon, et al. Major and micro nutrient advice for productive agricultural crops. 2008.

[3].Neil Dawson, Adrian Martin, and Thomas Sikor. Green revolution in subsaharan africa: implications of imposed innovation for the wellbeing of rural smallholders. World Development, 78:204-218, 2016.

[4].James W Hansen. Realizing the potential benefits of climate prediction to agriculture: issues, approaches, challenges. Agricultural systems, 74(3): 309-330, 2002.

[5].James W Hansen, Andries Potgieter, and Michael K Tippett. Using a general circulation model to forecast regional wheat yields in northeast australia. Agricultural and Forest Meteorology, 127(1-2):77-92, 2004.

[6].James W Hansen, Ashok Mishra, KPC Rao, Matayo Indeje, and Robinson Kinuthia Ngugi. Potential value of gcmbased seasonal rainfall forecasts for maize management in semi-arid kenya. Agricultural Systems, 101 (1-2):80-90, 2009.

[7].Peter Hoefsloot, Amor VM Ines, Jos van Dam, Gregory Duveiller, Francois Kayitakire, and James Hansen. Combining crop models and remote sensing for yield prediction: Concepts, applications and challenges for heterogeneous smallholder environments. 2012.

[8].James W Jones, Gerrit Hoogenboom, Cheryl H Porter, Ken J Boote,William D Batchelor, LA Hunt, Paul W Wilkens, Upendra Singh, Arjan J Gijsman, and Joe T Ritchie. The dssat cropping system model. European journal of agronomy, 18(3-4):235-265, 2003.

[9].DONALD KABERUKA et al. Rwanda vision 2020. 2000.

[10]. Allen C Kelley. The consequences of rapid population growth on human resource development: The case of education. In The impact of population growth on well-being in developing countries, pages 67-137. Springer, 1996.

[11]. David A Laird. The charcoal vision: a win-win-win scenario for simultaneously producing bioenergy, permanently sequestering carbon, while improving soil and water quality. Agronomy journal, 100(1):178-181, 2008.

[12]. Caroline Lesser and Evdokia Mois'e-Leeman. Informal cross-border trade and trade facilitation reform in subsaharan africa. 2009.

[13]. Ralf Metzler and Joseph Klafter. The random walk's guide to anomalous diffusion: a fractional dynamics approach. Physics reports, 339(1):1-77, 2000.

[14]. Francisco J Meza, James W Hansen, and Daniel Osgood. Economic value of seasonal climate forecasts for agriculture: review of ex-ante assessments and recommendations for future research. Journal of Applied Meteorology and Climatology, 47(5):1269-1286, 2008.

[15]. Alphonse Mutabazi. Rwanda country situational analysis. CAMCO Report, Nairobi Kenya, 2011.

[16]. H Partow, U Bloesch, G Bouma, N Brown, M Estrella, et al. Rwanda: from post conflict to environmentally sustainable development. United Nat ions Environment Programme, Nairobi, 2011.

[17]. AV Pukhovskiy. Ability of mitscherlich-spillman model to estimate critical soil phosphate levels. Int J Nutr Food Sci, 2:45-51, 2013.

[18]. William W Riggs, Kynda R Curtis, and Thomas R Harris. Importance \& Use of Enterprise Budgets in Agricultural Operations. University of Nevada, Nevada Cooperative Extension, 2005.

[19]. Rojas, Y Li, and R Cumani. An assessment using fao's agricultural stress index (asi): Understanding the drought impact of el nino on the global agricultural areas. 2014.

[20]. FS Royce, JW Jones, and JW Hansen. Model-based optimization of crop management for climate forecast applications. Transactions of the ASAE, 44(5):1319, 2001.

[21]. Rwanda. Economic Development and Poverty Reduction Strategy, 2008-2012. Ministry of Finance and Economic Planning, 2007.

[22]. B Searle, R Renquist, and B Bycroft. Agronomic factors affecting the variability of squash fruit weight. Agronomy NZ, 32:27-34, 2003. 
[23]. Samar R Sen et al. Decision-making and agriculture. In Decision-making and agriculture. Sixteenth International Conference of Agricultural Economics, Nairobi, Kenya, 26th July-4th August, pages 1-14, 1976.

[24]. MVK Sivakumar and J Hansen. Climate prediction and agriculture: summary and the way forward. In Climate Prediction and Agriculture, pages 1-13. Springer, 2007.

[25]. L Sun and MN Ward. Climate downscaling: assessment of the added values using regional climate models. In Climate Prediction and Agriculture, pages 15-29. Springer, 2007.

[26]. Johan FM Swinnen and Hamish R Gow. Agricultural credit problems and policies during the transition to a market economy in central and eastern europe. Food policy, 24(1):21-47, 1999.

[27]. V Zanella, BV Ortiz, K Thorp, F Morari, G Mosca, and G Hoogenboom. Combining crop sensing and simulation modeling to assess within-field corn nitrogen stress. In Precision agriculture'15, pages 165-177. Wageningen Academic Publishers, 2015. 